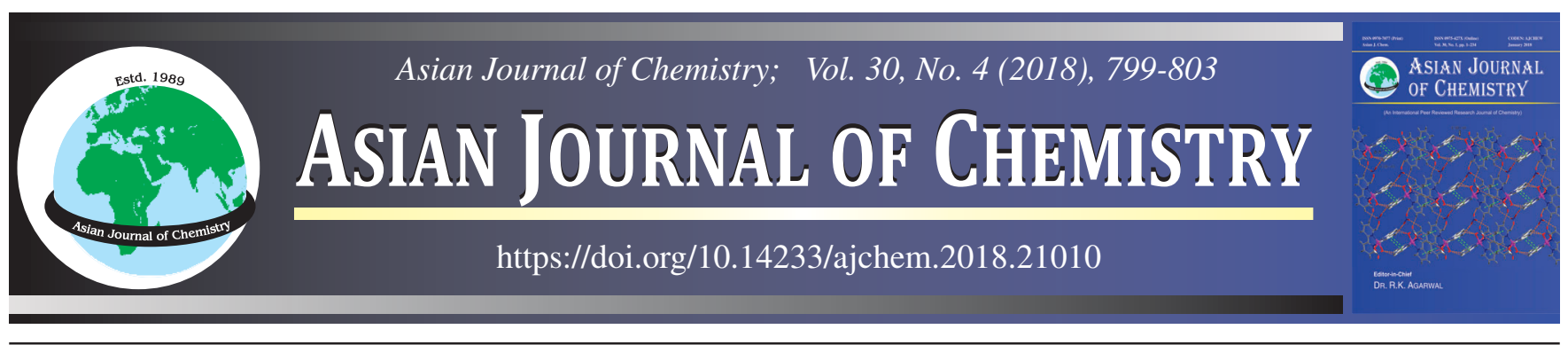

\title{
Synthesis and Characterization of Polyacid Doped Conducting and Non-Conducting Polymers: A Comparative Study
}

Bharath Sammanan, J Rosario Sekar and Jeyabalan Thavasikani*

Department of Chemistry, Sacred Heart College, Tirupattur-635 601, India

*Corresponding author: E-mail: jayabalandr@gmail.com

Received: 29 August 2017; Accepted: 28 November 2017; Published online: 28 February 2018;

Keggin type polyacid doped conducting (polyaniline) and non-conducting polymer (starch) with various molar ratios were synthesized by wet chemical method. The prepared compound is characterized by spectral techniques like FT-IR, SEM and XRD. The conductivity studies were also performed for the polyacid doped conducting and non-conducting polymer.

Keywords: Polyacid, Polyaniline, Starch, Bio-polymer, Conductivity.

\section{INTRODUCTION}

The polyacid (polyoxometalate) are early transition metal clusters, which is one of the most important growing fields in last decades with research and development in catalyzed reaction and various other applications $[1,2]$. The keggin structures are effective in thermally stable, luminescence [2], non-bonding interactions [3] and potential applications. The Keggin anion has high oxidation states, whereas variety of structures and chemical composition with various classes of metal-oxygen clusters [4]. Polyacid are composed of structures, $\mathrm{MO}_{6}$ units use to bridge by few oxygen atoms. Non-conducting polymers like natural biopolymers were used to incorporate Keggin type polyoxometalate shown magnetic behaviour of the molecules and accepting electron [5,6]. Biopolymers have many interesting biological applications in last decade whereas cellulose acetate hybrid nano-fibers acts have an effective catalyst for photo degradation [7]. Structural and electrochemical studies caused by ion (cation) exchange biopolymer particles [8]. The starch is present in a granular form and has different shapes and sizes depending on its botanical sources. Biopolymers will break down and some are suitable for domestic composting [9].

Polymers play an effective role in human life, our body is made of lot of polymers e.g. starch (polymer of glucose), proteins (polymer of amino acid), amylose etc. (polymer of glucose) [10]. Polyaniline has good conducting properties. In last few years conducting properties of polyaniline has been increased, high process ability and surface area [11]. The recent commercial applications of conducting polymers are in bio- sensors [12], fuel and solar cells [13], corrosion protective coatings [14]. The introduction polyacid into polymer gives an effective doping of polymer which causes charge balancing into the structure. Polyaniline doped polyacid composites as electro catalysts $[15,16]$, energy storage, nanostructure sensors [17] and electrochemical behaviour applications [18]. Doping of conducting polymers involve random dispersion or aggregation of doping in molar concentration in the disorder substrate high as $50 \%$ [19].

In this attempt, the polyacid doped conducting and nonconducting polymers have been prepared e.g., PCP-polyacid doped conducting polymer (polyaniline) and PBP-polyacid doped non-conducting polymer (starch). The morphological structures of conducting and non-conducting polymers revealed by scanning electron microscope (SEM) and promising peaks or functional groups shown in FT-IR. The crystallinity and grain size of synthesized sample is characterized by X-ray diffraction. Finally, the electrical conductivity shows interesting and higher conductive of polyacid doped conducting or non-conducting polymers.

\section{EXPERIMENTAL}

All common laboratory chemicals and reagents were purchased from Merck (potassium persulphate, hydrochloric acid, aniline, methanol, ammonium molybdate, manganese(II) sulphate, disodium hydrogen phosphate and concentrated nitric acid and are used without further purification.

Preparation of manganese doped polyacid: The complex is prepared by dissolving $1 \mathrm{~g}$ of manganese(II) sulphate and 
the oxidant potassium persulphate in $10 \mathrm{~mL}$ of distilled water. To this $4 \mathrm{~g}$ of ammonium molybdate and the $1 \mathrm{~g}$ of disodium hydrogen phosphate are added. To this concentrated nitric acid is added and stirred. Red coloured precipitate is obtained. The polyacid is filtered and dried.

Preparation of conducting polymer: The polyaniline is prepared by taking $4.564 \mathrm{~g}$ of potassium persulphate in $200 \mathrm{~mL}$ of $2.5 \mathrm{~N}$ hydrochloric acid. To this $2 \mathrm{~mL}$ of aniline is added dropwise with vigorous stirring at bath temperature. After addition of aniline $(0.5 \mathrm{~h})$, the complex is stirred for $2 \mathrm{~h}$. Dark bluish precipitate is obtained. The precipitate was washed with $5-10 \mathrm{~mL}$ of methanol and dried at $80^{\circ} \mathrm{C}$ in vacuum oven.

Synthesis of polyacid doped biopolymer compound (PBP)-I, II, III: $1 \mathrm{~g}$ of starch is dissolved in $10 \mathrm{~mL}$ of water and heated. Then $(0.5 \%)$ of polyacid dissolved in $3 \mathrm{~mL}$ of water is added slowly with vigorous stirring. The starch solution is added slowly to the prepared polyacid solution in a hot condition and then ultrasonicated for 20-30 min. The pale yellow precipitate formed is polyacid doped non-conducting polymers (PBP-I) is collected and dried; likewise the other two sample were synthesized as above procedure except that was used $(0.4 \%)$ of polyacid (PBP-II) and $(0.3 \%)$ of polyacid (PBP-III).

Synthesis of polyacid doped conducting polymer compound (PCP) - I, II, III: $2 \mathrm{~g}$ of poly aniline is dissolved in $50 \mathrm{~mL}$ of water and heated. $(0.5 \%)$ of poly acid dissolved in $3 \mathrm{~mL}$ of water is added slowly with vigorous stirring. The conducting polymer solution is added slowly to the prepared poly acid solution in a hot condition; after ultra-sonicated for 20-30 min then continues for $6 \mathrm{~h}$. The green colour precipitate formed is polyacid doped conducting polymers (PCP-I) filtered and dried; likewise the other two sample were synthesized as above procedure except that was used $(0.4 \%)$ of polyacid (PCP-II) and (0.3\%) of polyacid (PCP-III).

\section{RESULTS AND DISCUSSION}

The FT-IR spectra of free polyacid, polyaniline, polyacid doped conducting (polyaniline) and non-conducting (starch) polymers were given in Figs. 1 and 2. The tenta-tive assignment of bands of Keggin anion structured polyacid is given in Tables 1 and 2 . The band at $1643.6 \mathrm{~cm}^{-1}$ shows the stretching frequency of Mo-O bonds, at $1064.3 \mathrm{~cm}^{-1}$ indicates the presence of P-O bonds, M-O-M band is observed at 854.1 and one at 780-704 $\mathrm{cm}^{-1}$ indicates the stretching frequency of $\mathrm{M}-\mathrm{O}-\mathrm{X}(\mathrm{X}=\mathrm{Mn})$.

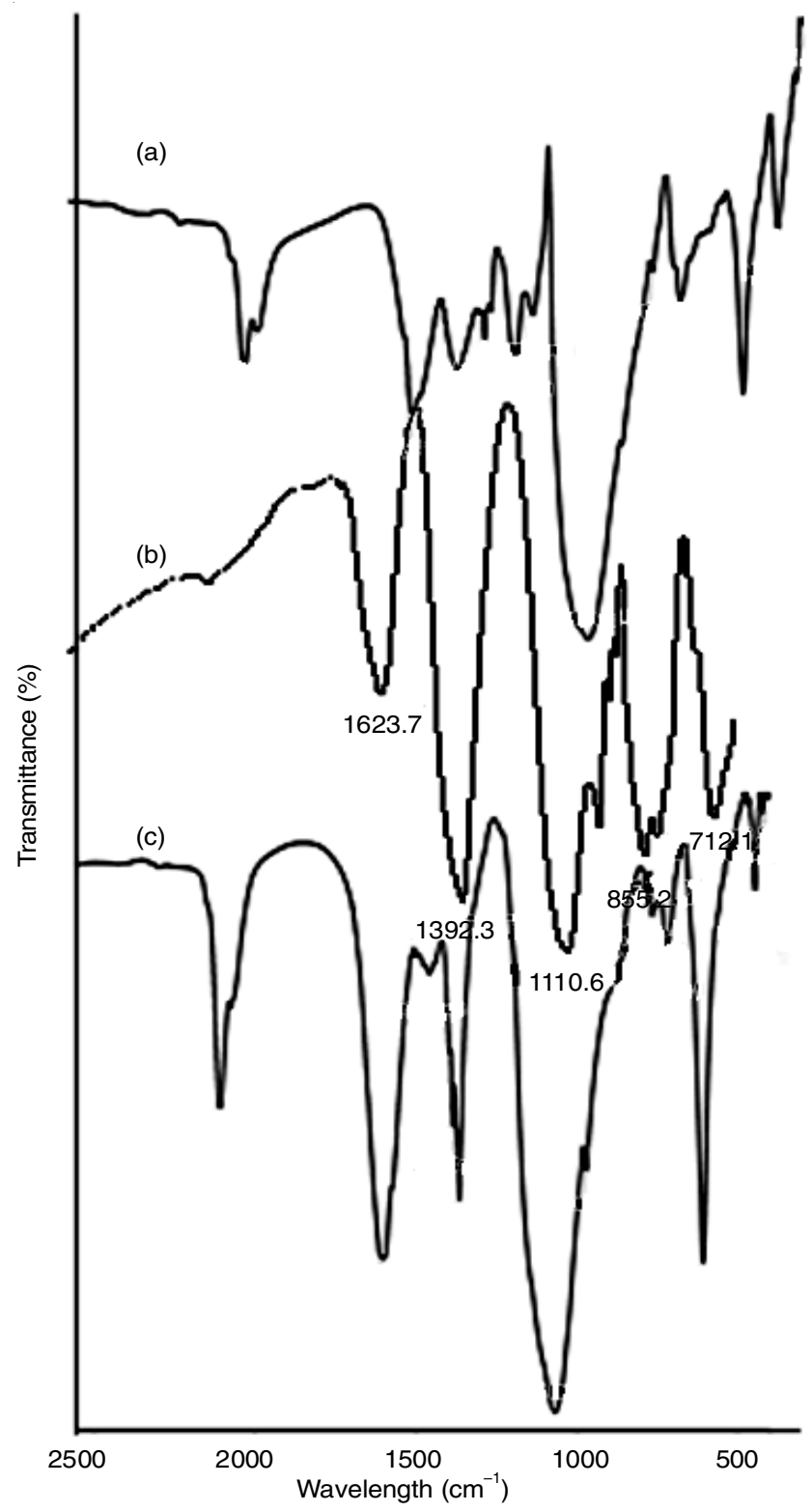

Fig. 1. FT-IR spectra (a) polyacid doped non-conducting bio-polymers PBP-I, (b) PBP-II and (c) PBP-III with different ratios

The upward shift in all the polyacid doped conducting (polyaniline) polymers is due to the charge interaction between the host-guest molecules. The downward shift of all polyacid doped

TABLE-1

IR SPECTRA $\left(\mathrm{cm}^{-1}\right)$ OF POLYACID DOPED BIO-POLYMER (STARCH) WITH DIFFERENT WEIGHT PERCENTAGE

\begin{tabular}{ccccc}
\hline Polyacid & $\begin{array}{c}\text { Polyacid doped } \\
\text { biopolymer (PBP-I) }\end{array}$ & $\begin{array}{c}\text { Polyacid doped } \\
\text { Biopolymer (PBP-II) }\end{array}$ & $\begin{array}{c}\text { Polyacid doped } \\
\text { biopolymer (PBP-III) }\end{array}$ & $\begin{array}{c}\text { Tentative band } \\
\text { assignments }\end{array}$ \\
\hline 1643.6 & 1603.1 & 1623.6 & 1599.3 & Mo-O \\
1164.3 & 1076.2 & 1060.0 & 1066.8 & P-O \\
854.1 & 879.8 & 855.2 & 764.6 & M-O-M \\
704.9 & 796.2 & 712.1 & 785.2 & M-O-X (X = Mn) \\
\hline
\end{tabular}

TABLE-2

IR SPECTRA $\left(\mathrm{cm}^{-1}\right)$ OF POLYACID DOPED CONDUCTING (POLYANILINE) POLYMERS WITH DIFFERENT WEIGHT PERCENTAGE

\begin{tabular}{ccccc}
\hline Polyacid & (PCP-I) & (PCP-II) & (PCP-III) & Tentative band assignments \\
\hline 1605.50 & 1610.78 & 1610.78 & 1605.15 & Mo-O \\
1033.30 & 1075.98 & 1076.91 & 1076.24 & P-O \\
936.37 & 971.85 & 970 & 879.86 & M-O-M \\
708.30 & 792.96 & 795.11 & 796.29 & M-O-X (X=Mn) \\
\hline
\end{tabular}




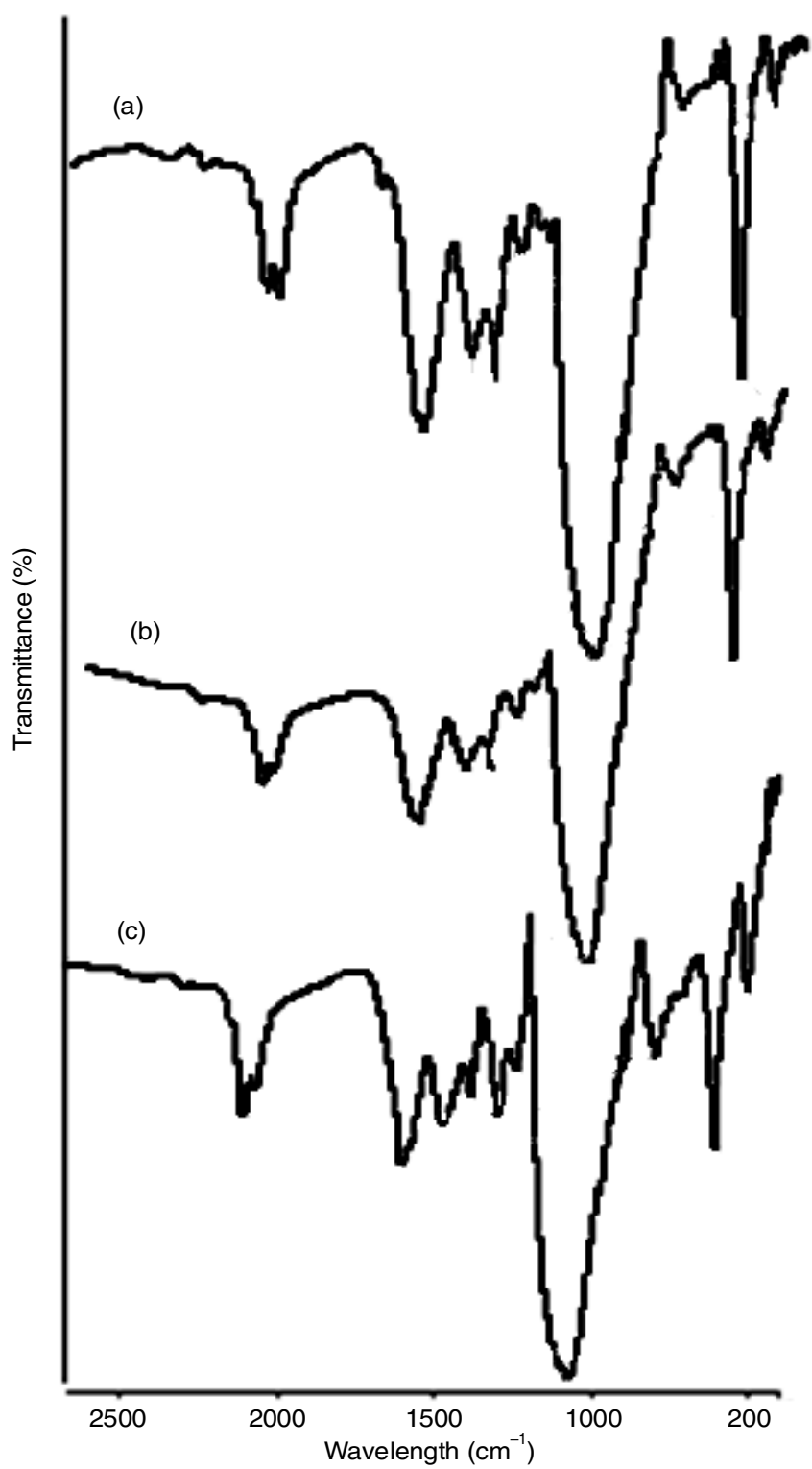

Fig. 2. FT-IR spectra (a) polyacid doped conducting polymers PCP-I, (b) PCP-II and (c) PCP-III with different weight percentage ratios

non-conducting (starch) polymers is due to the formation of intercalated compound, which in turn affects the P-O stretching frequency.

The morphology of polyacid doped conducting and nonconducting polymers has been investigated by SEM (Figs. 3 and 4). The polyacid shows clusters shaped morphological structure has formed (Fig. 3a). In polyacid doped non-conducting polymers (PBP-I, II, III) with different weight percentage are shown in Fig. 3a-c is around $500 \mathrm{~nm}$ (micrometers) scale, whereas shows a bulk size due to presence of bio-polymers (starch) which has been confirmed in polyacid. The SEM of the polyaniline shows morphological of uniform chain structure (Fig. 4a). The diameter of the polyacid doped polyaniline (PCP-I, II, III) confirms the dopant crystal in chain structure of polyaniline (Fig. 4b-d) is nanometer scale, which gives around $70-100 \mathrm{~nm}$.

The XRD analysis (Figs. 5 and 6) shows pattern of polyacid was appeared at 15.11, 19.79, 23, 25, 28, 30, 32 and 40. The polyacid doped conducting polymer at different weight

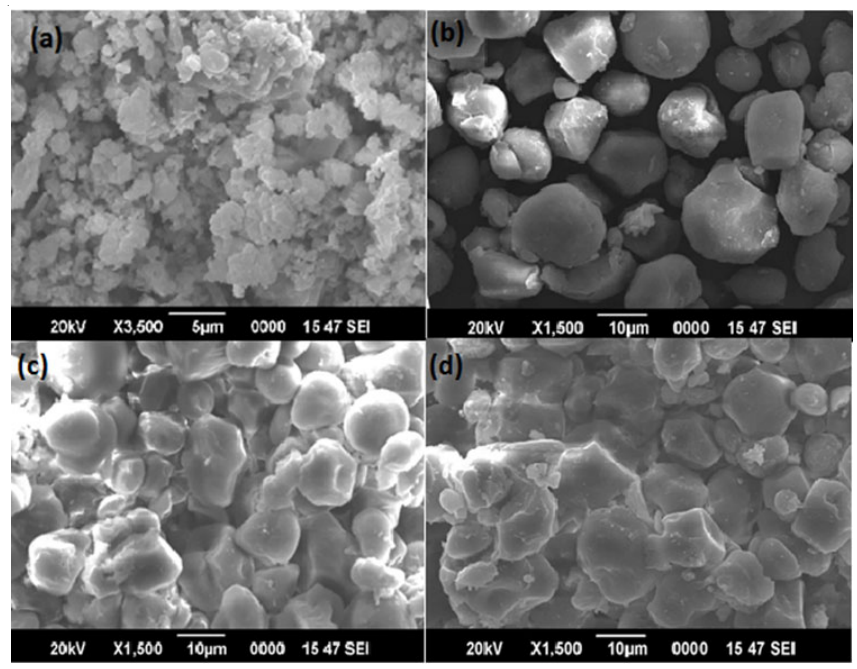

Fig. 3. SEM images of morphological structure of Non-conducting (starch) bio-polymers (a) polyacid (b) PBP-I (c) PBP-II (d) PBP-III
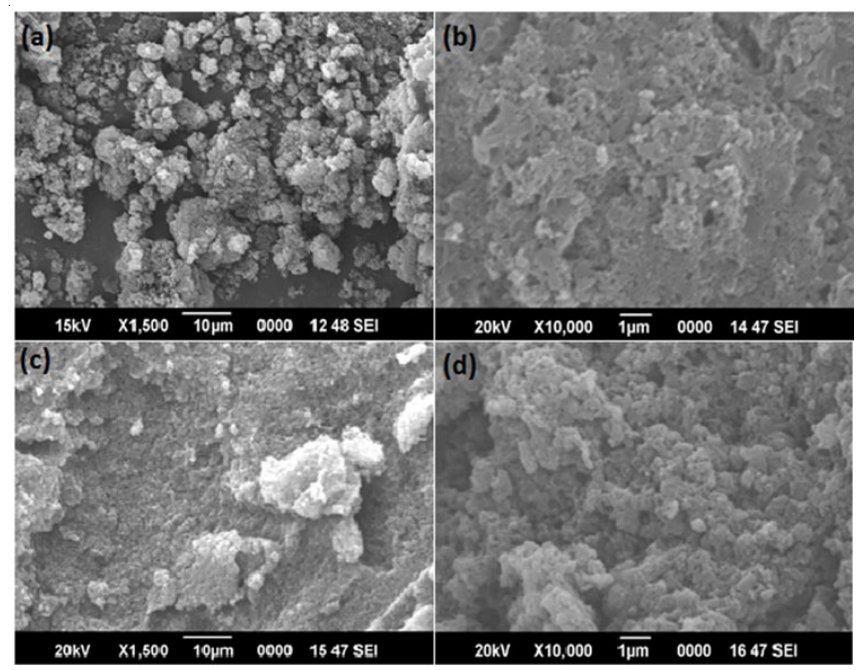

Fig. 4. SEM images of morphological structure of conducting (polyaniline) polymers (a) polyaniline (b) PCP-I (c) PCP-II (d) PCP-III

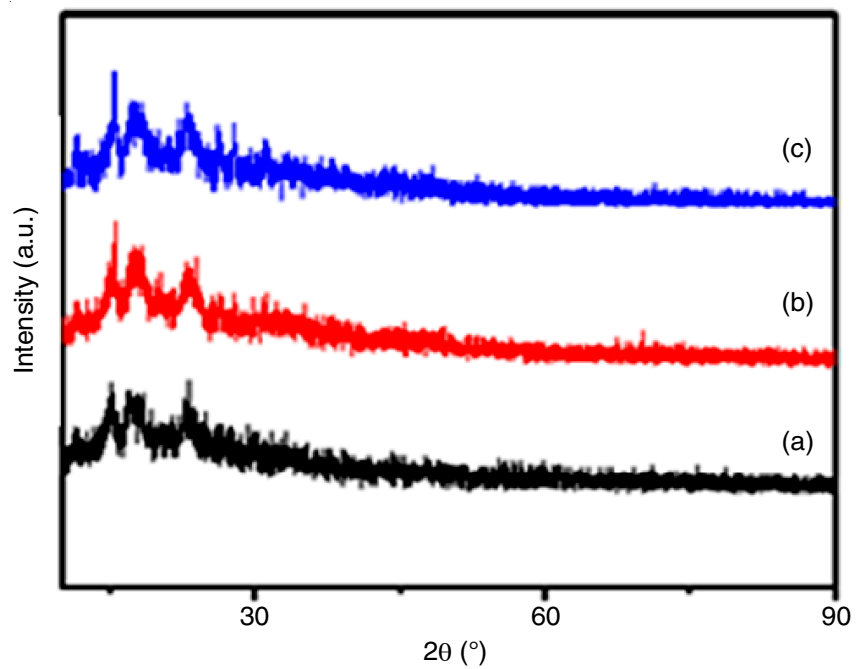

Fig. 5. XRD pattern (a) polyacid doped non-conducting polymers PBP-I, (b) PBP-II, (c) PBP-III and (d) polyacid

percentage of $(0.6 \%)$ shows peaks at $9.45,14.90,25.55$ and 58.96. $(0.8 \%)$ peaks at $14.69,20.22,25.31,25.38,28.16$ and 


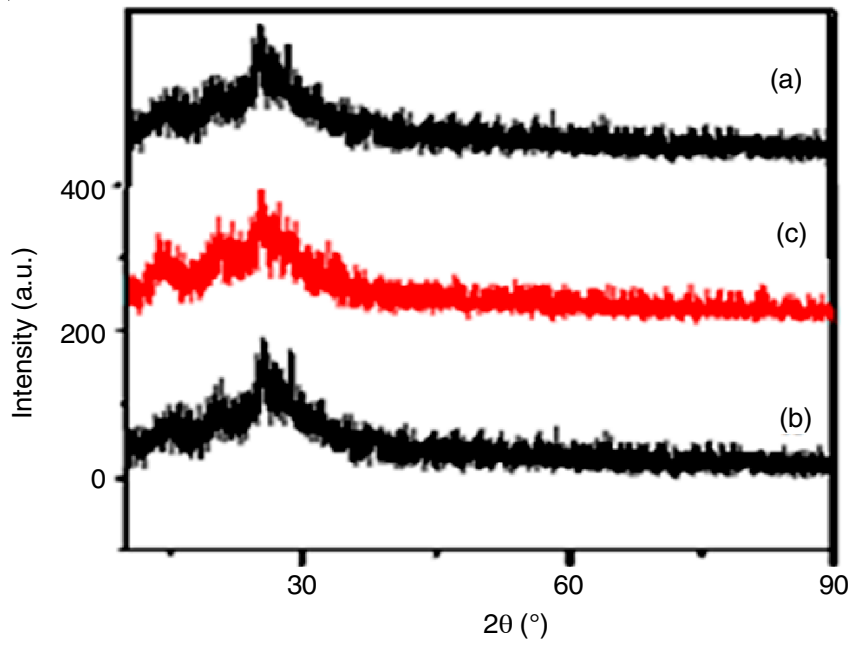

Fig. 6. XRD pattern (a) conducting [polyaniline] polymers (b) polyacid doped conducting polymer PCP-I, (c) PCP-II

58.14 as shown in Fig. 6. The pattern of polyacid gives prominent peaks at 11,15, 17 and 23, representing the crystal planes of (200), (100), (111), (1 1 2) of polyacid respectively. Polyacid doped biopolymer (curve a, b and c) shows some sharps peaks at 11, 15.2, 17.7 and 23.2, representing the crystal plane of doped biopolymer respectively (Fig. 5). The sharpness of the peaks represents the degree of orientation of the polymer chains in that crystal plane and the intensity represents the population of crystal lattices in that plane. The grain size and crystallinity of polyacid doped conducting polymers and non-conducting bio-polymers are shown in Tables $3 \mathrm{a}$ and $3 \mathrm{~b}$.

Conductivity studies: The data is plotted and is given in Fig. 7a,b. The curve showing that the evolution of the electric conductivity (sigma) according to the doping level follows an exponential form. Indeed the values of the electrical conductivity is in the order of $10^{-4} \mathrm{~S} \mathrm{~cm}^{-1}$ for doped conducting polymer whereby a high conductivity value of $2.7 \times 10^{-2} \mathrm{~S} \mathrm{~cm}^{-1}$ for the electrical conductivity value of polyacid doped conducting polymer (PCP-I) and (PCP-II) are shown in Fig. 7a. In case of the biopolymers (non-conducting) the conductivity value is $2.58 \times 10^{-4} \mathrm{~S} \mathrm{~cm}^{-1}$ and for the polyacid doped biopolymer

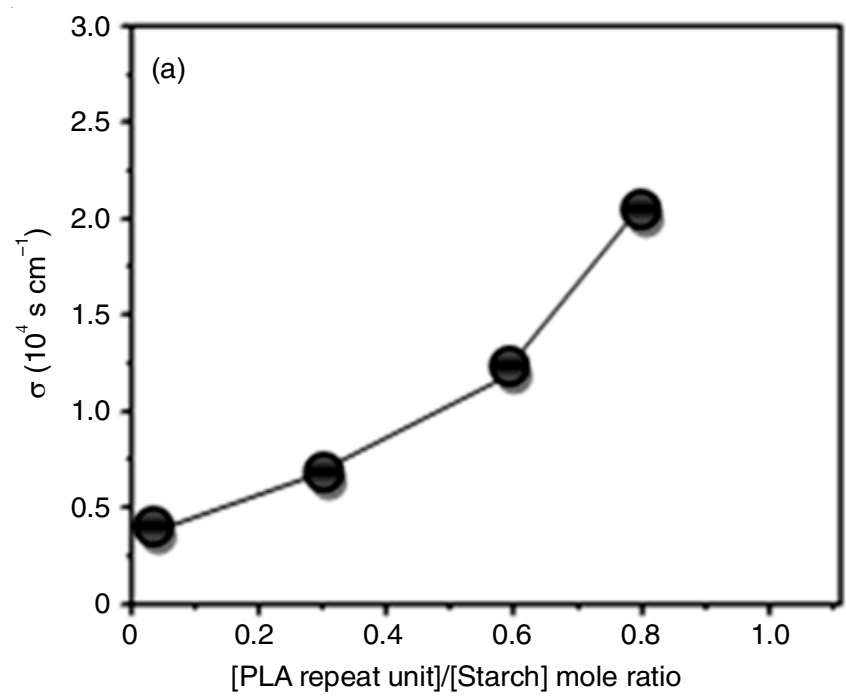

TABLE-3a

CRYSTALLINE OR GRAIN SIZE OF POLYACID DOPED CONDUCTING POLYMERS WITH DIFFERENT WEIGHT PERCENTAGE

\begin{tabular}{ccc}
\hline Samples & 20 value & Grain size value $(\mathrm{nm})$ \\
\hline \multirow{2}{*}{ Manganese doped } & 28.15 & 1.2 \\
polyacid & 30.12 & 1.7 \\
& 40.49 & 1.6 \\
\hline \multirow{2}{*}{ Polyaniline } & 11.13 & 1.4 \\
& 17.80 & 1.3 \\
& 26.86 & 1.6 \\
\hline \multirow{2}{*}{ Polyacid-conducting } & 9.45 & 4.4 \\
polymer (PCP-I) & 14.90 & 7.4 \\
& 25.55 & 1.2 \\
\hline \multirow{2}{*}{ Poly acid-conducting } & 14.69 & 4.4 \\
polymer (PCP-II) & 25.31 & 8.5 \\
& 25.38 & 7.7 \\
\hline
\end{tabular}

\begin{tabular}{|ccc}
\hline \multicolumn{3}{c}{ TABLE-3b } \\
\multicolumn{3}{|c}{ CRYSTALLINE OR GRAIN SIZE OF POLYACID } \\
DOPED NON-CONDUCTING POLYMERS WITH \\
\multicolumn{2}{c}{ DIFFERENT WEIGHT PERCENTAGE } \\
\hline Samples & 20 value & 'D'-Grain size values (nm) \\
\hline & 9.55 & 2.2 \\
Polyacid & 11.19 & 1.8 \\
& 15.45 & 1.9 \\
& 27.58 & 2.2 \\
\hline Polyacid doped & 15.06 & 8.0 \\
biopolymer (0.2) \% & 17.14 & 4.4 \\
(PBP-I) & 23.01 & 5.7 \\
\hline Polyacid doped & 15.20 & 8.6 \\
biopolymer (0.4) \% & 17.73 & 4.3 \\
(PBP-II) & 23.16 & 4.7 \\
\hline Polyacid doped & 15.36 & 6.7 \\
biopolymer (0.6) \% & 17.45 & 4.2 \\
(PBP-III) & 22.90 & 5.2 \\
\hline
\end{tabular}

the conductivity value found to be $2.23 \times 10^{-3} \mathrm{~S} \mathrm{~cm}^{-1}$ for (PBP-I) and (PBP-II) is shown in Fig. 7b. The enhanced conductivity of polyacid doped conducting and non-conducting polymer is due to the presence of electron rich center in the polyacid.

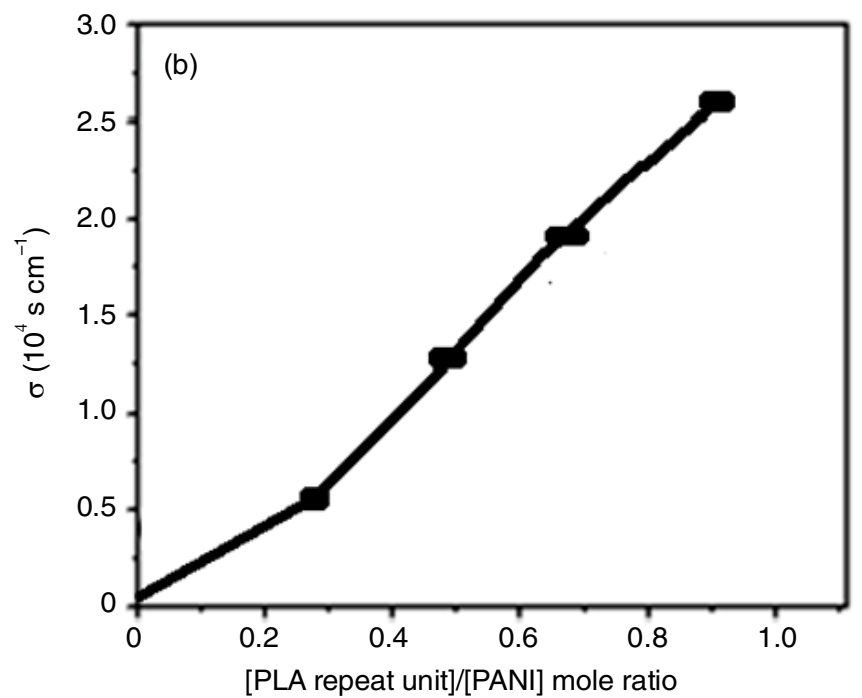

Fig. 7. Conductivity studies of (a) Non-conducting (starch) bio-polymers [PBP] and (b) polyacid doped conducting (polyaniline) polymers [PCP] 


\section{Conclusion}

The compounds namely polyacid, polyacid doped biopolymers (PBP-I, II and III) and polyaniline, polyacid doped conducting polymers (PCP-I, II and III) were synthesized and characterized by IR and SEM. The IR data showed that the characteristic splitting of peaks which are due to the formation of host-guest compound. The SEM morphology supports the formation of polyacid doped biopolymer. The XRD, conductivity studies also confirmed the formation of polyacid doped conducting (polyaniline) and non-conducting (starch) polymer.

\section{ACKNOWLEDGEMENTS}

The financial support from UGC, SERO, Hyderabad, India and Donbosco Research Grant, Sacred Heart College, Tirupattur, India is greatly appreciated.

\section{REFERENCES}

1. $\quad$ S.-S. Wang and G.-Y. Yang, Chem. Rev., 115, 4893 (2015); https://doi.org/10.1021/cr500390v.

2. J. Kafawein, H.K. Juwhari and M.A. AlDamen, J. Clust. Sci., 26, 1683 (2015);

https://doi.org/10.1007/s10876-015-0867-9.

3. S. Upreti and A. Ramanan, Cryst. Growth Des., 6, 2066 (2006); https://doi.org/10.1021/cg0601610.

4. M.T. Pope and A. Muller, Angew. Chem. Int. Ed. Engl., 30, 34 (1991); https://doi.org/10.1002/anie.199100341.

5. T. Ito, H. Yashiro and T. Yamase, Langmuir, 22, 2806 (2006); https://doi.org/10.1021/la052972w.
6. W. Salomon, Y. Lan, E. Rivière, S. Yang, C. Roch-Marchal, A. Dolbecq, C. Simonnet-Jégat, N. Steunou, N. Leclerc-Laronze, L. Ruhlmann, T. Mallah, W. Wernsdorfer and P. Mialane, Chem. Eur. J., 22, 6409 (2016); https://doi.org/10.1002/chem.201601356.

7. M. Rohani, F.F. Bamoharram, M. Khosravi, J. Baharara and M.M. Heravi, J. Exp. Nanosci., 12, 1 (2017); https://doi.org/10.1080/17458080.2016.1246754.

8. M.S. Malik, A.A. Qaiser and M.A. Arif, RSCAdvances, 6, 115046 (2016); https://doi.org/10.1039/C6RA24594C.

9. R. Chandra and R. Rustgi, Biodegrad. Polymers Prog. Polym. Sci., 23, 1273 (1998); https://doi.org/10.1016/S0079-6700(97)00039-7.

10. D.A. Seanor, Electrical Properties of Polymers, Academic Press, p. 15 (2013).

11. C.O. Baker, X. Huang, W. Nelson and R.B. Kaner, Chem. Soc. Rev., 46, 1510 (2017); https://doi.org/10.1039/C6CS00555A.

12. A. Morrin, F. Wilbeer, O. Ngamna, S.E. Moulton, A.J. Killard, G.G. Wallace and M.R. Smyth, Electrochem. Commun., 7, 317 (2005); https://doi.org/10.1016/j.elecom.2005.01.014.

13. J. Jang, J. Bae and K. Lee, Polymer, 46, 3677 (2005); https://doi.org/10.1016/j.polymer.2005.03.030.

14. N. Plesu, G. Ilia, A. Pascariu and G. Vlase, Synth. Met., 156, 230 (2006); https://doi.org/10.1016/j.synthmet.2005.11.006.

15. G. Bidan, M. Lapkowski and J.P. Travers, Synth. Met., 28, 113 (1989); https://doi.org/10.1016/0379-6779(89)90507-9.

16. G.G. Papagianni, D.V. Stergiou, G.S. Armatas, M.G. Kanatzidis and M.I. Prodromidis, Sens. Actuators B, 173, 346 (2012); https://doi.org/10.1016/j.snb.2012.07.020.

17. S. Herrmann, C. Ritchie and C. Streb, Dalton Trans., 44, 7092 (2015); https://doi.org/10.1039/C4DT03763D.

18. X. Xia, D. Fan, B. An, Y. Cai and Q. Wei, J. Mol. Liq., 206, 335 (2015); https://doi.org/10.1016/j.molliq.2015.03.011.

19. A. G. Macdiarmid, R.J. Mammone, J.R. Krawczyk and S.J. Porter, Mol. Cryst. Liq. Cryst., 105, 89 (1984); https://doi.org/10.1080/00268948408071645. 